\title{
Research Paper: Analyzing Toxic Chemical Components in Illegal Alcoholic Beverages
}

\author{
Mahmoud Abbasi $^{1}$ (D), Kambiz Soltaninejad ${ }^{1^{*}}$ (D) \\ 1. Department of Forensic Toxicolaogy, Legal Medicine Research Center, Legal Medicine Organization, Tehran, Iran
}

\begin{tabular}{|c|c|}
\hline $\begin{array}{l}\text { Use your device to scan } \\
\text { and read the article online }\end{array}$ & $\begin{array}{l}\text { Jitation: Abbasi M, Soltaninejad K. Analyzing Toxic Chemical Components in Illegal Alcoholic Beverages. International } \\
\text { Journal of Medical Toxicology and Forensic Medicine. 2020; 10(3):29331. https://doi.org/10.32598/ijmtfm.v10i3.29331 } \\
\text { doi https://doi.org/10.32598/ijmtfm.v10i3.29331 }\end{array}$ \\
\hline
\end{tabular}

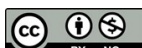

Article info:

Received: 08 Mar 2020

First Revision: 18 Mar 2020

Accepted: 01 Jul 2020

Published: 12 Oct 2020

\section{Keywords:}

Adulteration, Alcoholic beverages, Chemical analysis, Methanol

\section{ABSTRACT}

Background: The illegal production of alcoholic beverages, due to the non-standard conditions, increases the risk of producing counterfeit and toxic products. The chemical analysis of toxic components in illegally-produced alcoholic beverages is necessary for each country. The present study aimed to identify the existence of methanol and other potentially toxic compounds in the seized illegally-produced alcoholic beverages.

Methods: In this descriptive laboratory-based study, we analyzed the toxic chemical components in sized illegally-produced alcoholic beverages, submitted to the Forensic Toxicology Laboratory of the Legal Medicine Center of Markazi Province, Arak City, Iran, in a year. A total of 100 seized illegally-produced alcohol beverage samples were collected. The qualitative and quantitative analysis of ethanol, methanol, 1-propanol, 2-propanol, and acetone was performed by the Gas Chromatography-Flame Ionization Detection (GC-FID) method.

Results: Methanol was detected in $6 \%$ of the evaluated samples (concentration range: $1.2 \%$ $12 \% \mathrm{v} / \mathrm{v}$ ). Acetone was detected in two of the studied samples (mean concentration: $0.7 \% \mathrm{v} / \mathrm{v}$ ), and 2-propanol with a concentration of $0.5 \% \mathrm{v} / \mathrm{v}$ was found in one sample. Besides, ethanol was detected in all explored samples (mean concentration: $24 \% \mathrm{v} / \mathrm{v}$ ).

Conclusion: Methanol was the main toxic chemical component in illegal alcoholic beverages; thus, it should be considered in public health policy and prevention programs in the country.

\section{Introduction}

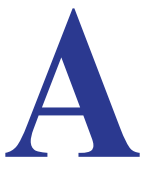

lcohol consumption is a major risk factor from clinical and forensic medicine aspects. Previous studies have suggested that alcohol consumption significantly affects disease morbidity and mortality, worldwide $[1,2]$. Alcohol use is related to negative consequences on the socio-economic and health issues through direct acute and chronic toxic effects, poisoning, and dependence [3]. For example, a causal relationship was demonstrated between alcohol use and generating different cancers, such as gastrointestinal cancers (oral cavity, esophagus, hepatic cell carcinoma, pancreas, \& colorectal carcinoma), lung cancers (larynx \& pharynx carcinoma), and breast cancer [4]. From a medico-legal

* Corresponding Author:

Kambiz, Soltaninejad, PhD.

Address: Department of Forensic Toxicology, Legal Medicine Research Center, Legal Medicine Organization, Tehran, Iran.

Tel: +98 (21) 55613731

E-mail: kamsoltaninejad@gmail.com 
aspect, alcohol is identified as a risk factor in traffic accidents and high-risk behaviors, like suicide [5, 6]. Furthermore, alcohol use disorders were recognized as the most frequent substance use disorder type, globally [1].

The quality of alcoholic beverages, along with other factors, such as the volume and patterns of drinking crucially impact health consequences in drinkers [3, 7]. In most countries, the availability of standard alcoholic beverages is among the primary control policies on alcohol consumption and harm reduction. However, manufacturing illegal alcoholic drinks, due to economic benefits, remains a common problem, worldwide. In Islamic countries, alcohol use is prohibited and serves a punishable act due to the legal and religious laws [8]. Despite this limitation, in these countries, producing legal alcoholic beverages is common [9].

Methanol, as the most common and main alcohol type, is used in producing counterfeit and illegal alcoholic beverages instead of ethanol, i.e., due to its low cost $[7,8]$. Moreover, it is produced during the non-standard procedure of alcoholic beverages production due to the fermentation of pectin and sugars. Accordingly, methanol poisoning is a frequent consequence of consuming illegal and counterfeit alcoholic drinks. Therefore, sporadic and epidemic methanol poisoning cases were reported worldwide, as a result of using illegal alcoholic products [1012]. Thus, consuming illegal and homemade alcoholic beverages, especially in low-income individuals, is considered as a potential source of methanol poisoning [13].

Aldehydes (e.g., acetaldehyde) and higher alcohols (e.g., 1-propanol, 2-propanol, 1-butanol, \& isoamyl alcohol) are manufactured as the by-products of fermentation in alcoholic beverages. The existence of the higher alcohols and aldehydes in illegal alcoholic products might lead to an increased incidence of cancer and liver diseases in drinkers [13].

Annually, several cases of methanol poisoning and fatality induced by illegal and homemade alcoholic beverages consumption are reported in Iran. However, there are scant data on the chemical composition of these beverages in Iran $[14,15]$.

Therefore, we aimed to analyze methanol and other toxic alcohols and aldehydes, as main toxic chemical components in seized illegally alcoholic beverages.

\section{Materials and Methods}

During one year (2017), all illegal alcoholic beverages seized by the police, submitted to the Forensic Toxicology Laboratory of the Legal Medicine Center of Markazi Province (Arak City, Iran) were analyzed.

Methanol, ethanol, 1-propanol, 2-propanol, acetone, and double-distilled water were obtained (Merck Co.; Darmstadt, Germany). Besides, they were used as standards for qualitative and quantitative analysis of the collected samples. All chemicals were of High-Performance Liquid Chromatography (HPLC) grade.

Each product's sample was decanted into a volumetric flask and organoleptic evaluations [e.g., appearance, volume, odor, color, \& pH (pH meter, Methrom, Switzerland)] and labeling the information (if available) was conducted.

For clear samples, we used $0.4 \mu \mathrm{L}$ of sample diluted by the double-distilled water until the final volume reaches to $1 \mathrm{~mL}$. For turbid samples, a $10 \mathrm{~mL}$ of the sample was filtered by Millipore ${ }^{\circledR}$ membrane filter $(0.45 \mu \mathrm{m}$ pore size; Merck Co, Germany). Then, it was diluted with double distilled water, and $2 \mu \mathrm{L}$ of the sample was directly injected into the Gas Chromatography-Flame Ionization Detector (GC-FID).

The samples were analyzed on a GC-FID system (6000 series, Yong Lin, Anyang, South Korea). The separations of methanol, ethanol, 1-propanol, 2-propanol, and acetone (target compounds) were accomplished using a nickel tubing GC packed column (2.0 m, L, $2.0 \mathrm{~mm}$, ID), packed with Porapak Q (80/100 mesh) (Agilent, USA). Briefly, the GC-FID parameters were as follows: carrier gas: nitrogen (flow rate: $20 \mathrm{~mL} / \mathrm{min}$ ); zero air with hydrogen gas, as the combustion gas; injector temperature was equal to $180^{\circ} \mathrm{C}$, detector temperature was set at $200^{\circ} \mathrm{C}$, and oven temperature was considered as $120^{\circ} \mathrm{C}$. The resulted signals and data acquisition systems were processed by a YLClarity software package (Yung Lin, South Korea).

The quantitative analysis of the target compounds was performed following the calibration of the GC-FID system. The calibration curves were obtained by the standard mixtures, containing individual target compounds at the concentrations of $0.1,0.2,0.4,0.6,0.8$, and 1 volumetric percentage $(\mathrm{v} / \mathrm{v} \%)$. The concentrations of target compounds in volume-volume percent $(\mathrm{v} / \mathrm{v} \%)$ were calculated by the data analysis software according to the calibration curves. Data analysis was performed by SPSS. 


\section{Results}

In total, 100 samples (the cumulative volume of the samples: 356 liters) were analyzed. The organoleptic evaluation results are listed in Table 1 . The obtained data suggested that most samples were packaged in plastic bottles $(61 \%)$ with a volume ranging between $50-400$ $\mathrm{mL}(89 \%)$. The $\mathrm{pH}$ range of the studied samples was equal to $2.5-6.1$; most of the sample $(58 \%)$ had a $\mathrm{pH}$ of 3.1-4. Most of the investigated samples (65\%) had a clear appearance. Most of them (22\%) were odorless, followed by an ethanol smell (20\%) (Table 1).

The composition and concentrations of target volatile substances in the products are presented in Table 2. Methanol and acetone were detected in 6(6\%) and $2 \%$ of the studied samples, respectively. Additionally, 2-propanol was detected in one sample and 1-propanol was not detected in any samples. Ethanol was detected in all of the explored samples (Table 2).

The average concentration of ethanol in the samples was calculated as $24 \% \mathrm{v} / \mathrm{v}$, ranging from $1 \%$ to $55 \% \mathrm{v} / \mathrm{v}$. The alcoholic strength and chemical composition data in 9 of the seized alcoholic samples are outlined in Table 3. The methanol concentrations of samples ranged from $1.2 \%-12 \% \mathrm{v} / \mathrm{v}$. However, acetone was detected in two samples with ethanol (Table 3).

\section{Discussion}

The ingestion of illegal alcoholic beverages is a prevalent cause of sporadic and epidemic methanol poisoning, worldwide [8-12]. In Iran, methanol poisoning remains a serious problem; almost all methanol fatalities are related to consuming methanol in illegal and homemade alcoholic beverages $[8,11,16]$. In Iran, the production and ingestion of alcoholic beverages are prohibited. Therefore, illegally-produced and smuggled alcoholic beverages are frequently available and considered as a major health threat.

According to different methods of manufacturing homemade products, the products' quality and ingredients are quite different from standard alcoholic beverages as well as each other. Therefore, the ingredients of these products are not standard for ethanol concentrations, methanol, and other components [9]. Considering the low cost of these products, consuming illegal and homemade alcoholic preparations is common. Like other countries, it is responsible for high morbidity and mortality rates in Iran [9-11]. The methanol mass poi- soning caused by illegal alcoholic beverages uptake was reported in Iran $[9,11,16]$.

A significant data obtained in the current study was detecting methanol in $6 \%$ of the analyzed samples; a majority of them $(67 \%)$ had a toxic concentration of methanol. A study in Mashhad City, Iran detected methanol in only $<0.5 \%$ ( 4 samples among a total of 886 samples) of the explored beverages [14]. There was an obvious rise in the frequency of methanol contaminated alcoholic beverages in Iran. Moreover, the methanol concentration exceeding $2 \% \mathrm{v} / \mathrm{v}$ in alcoholic beverages, induces toxicity [17]. Additionally, the European Union limit for naturally-produced methanol in alcoholic beverages is $0.4 \% \mathrm{v} / \mathrm{v}$ for methanol and $40 \% \mathrm{v} / \mathrm{v}$ for ethanol [17].

Accordingly, in our study, 4 samples exceeding this level were identified that could be considered as toxic products. According to the recent high prevalence of methanol poisoning in Iran, methanol-contaminated illegal and homemade alcoholic beverages are largely distributed in the domestic black market [18]. Our result was inconsistent with a study in Turkey. In this study, methanol has been detected in $75 \%$ of analyzed illegal alcoholic samples; however, its concentration fell in the acceptable limits, according to the Turkish Food Codex [9].

Ethanol is the main ingredient of alcoholic beverages and was detected in all investigated samples. This finding was in line with a study on the analysis of compositions of illegal alcoholic beverages in Tehran City, Iran [15]. The determination of ethanol concentration in legal alcoholic beverages is a crucial control point from safety and economic concerns [19]. Previous studies have indicated that illegal and unrecorded alcoholic products have higher ethanol levels than those of the legal production $[9,14]$. These findings are in concordance with our study in which the ethanol mean concentration was detected as $24 \% \mathrm{v} / \mathrm{v}$.

In our study, 2-propanol, as long-chain alcohol, has been detected in one sample. This result is consistent with a study that reported the presence of hepatotoxic long-chain aliphatic alcohols in illegal alcoholic products [20]. According to previous studies, the presence of long-chain alcohols in illegal and homemade alcoholic beverages should be considered as a risk factor for morbidity and mortality due to generating hepatic disorders and cancers $[1,2]$.

Acetone is another toxic component, i.e., detected in two studied samples. It is produced by the fermentation process due to the oxidation of 2-propanol during homemade 
Table 1. The organoleptic characteristics of seized illegal alcoholic products $(\mathrm{N}=100)$

\begin{tabular}{|c|c|c|}
\hline \multicolumn{2}{|c|}{ Organoleptic Parameter } & \multirow{2}{*}{$\begin{array}{c}\text { Frequency (\%) } \\
61\end{array}$} \\
\hline \multirow{4}{*}{ Packaging type } & Plastic bottle & \\
\hline & Glass bottle & 21 \\
\hline & Plastic flask & 2 \\
\hline & Doypack & 16 \\
\hline \multirow{2}{*}{ The existence of packaging label } & Yes & 51 \\
\hline & No & 49 \\
\hline \multirow{8}{*}{ Sample volume (mL) } & $<50$ & 29 \\
\hline & $51-100$ & 23 \\
\hline & $101-200$ & 15 \\
\hline & $201-300$ & 8 \\
\hline & $301-400$ & 14 \\
\hline & $401-500$ & 4 \\
\hline & $501-1000$ & 5 \\
\hline & $>1000$ & 2 \\
\hline \multirow{8}{*}{$\mathrm{pH}$} & $<3$ & 6 \\
\hline & $3.1-3.5$ & 18 \\
\hline & $3.6-4$ & 50 \\
\hline & $4.1-4.5$ & 13 \\
\hline & $4.6-5$ & 4 \\
\hline & $5.1-5.5$ & 5 \\
\hline & $5.6-6$ & 3 \\
\hline & $>6$ & 1 \\
\hline \multirow{5}{*}{ Color } & Cherry-red & 11 \\
\hline & Brown & 34 \\
\hline & Yellow & 14 \\
\hline & Red & 16 \\
\hline & Colorless & 25 \\
\hline \multirow{3}{*}{ Appearance } & Clear & 65 \\
\hline & Semi-clear & 21 \\
\hline & Opaque & 14 \\
\hline \multirow{7}{*}{ Odor } & Orange-like & 11 \\
\hline & Cherry-like & 19 \\
\hline & Rotten apple & 8 \\
\hline & Banana & 12 \\
\hline & Alcohol & 20 \\
\hline & Vinegar & 8 \\
\hline & Odorless & 22 \\
\hline
\end{tabular}


Table 2. The chemical compositions and qualitative analysis of seized illegal alcoholic products

\begin{tabular}{cccc}
\hline Substance & No. of Samples $(\mathbf{N}=\mathbf{1 0 0})$ & $\begin{array}{c}\text { Concentration }(\mathbf{v} / \mathbf{v} \%) \\
\text { Mean } \pm \text { SD }\end{array}$ & $\begin{array}{c}\text { Concentration range (v/v\%) } \\
\text { (Min-Max) }\end{array}$ \\
\hline Methanol & $* 6$ & $4.3 \pm 3.9$ & $1.2-12$ \\
Ethanol & $* 100$ & $24 \pm 13.2$ & $1-55$ \\
Acetone & $* 2$ & 0.7 & $0.6-0.8$ \\
2-Propanol & $* 1$ & 0.5 & 0.5 \\
1-Propanol & ND & - & ND \\
\hline
\end{tabular}

ND: Not detected. $n^{*}$ : Number of the samples containing the target compound. SD: Standard Deviation.

Table 3. The volume concentrations of methanol, acetone, and 2-propanol in 9 samples of seized alcoholic beverages

\begin{tabular}{ccccc}
\hline \multirow{2}{*}{ Code of Sample } & \multicolumn{2}{c}{ Concentration (\%v/v) } \\
\cline { 2 - 4 } & Ethanol & Methanol & 2-Propanol & Acetone \\
\hline S01 & 46 & 1.2 & ND & ND \\
S02 & 23 & 3 & ND & ND \\
S03 & 35 & 2 & ND & ND \\
S04 & 39 & 3.4 & ND & ND \\
S05 & 16 & 4 & ND & ND \\
S06 & 22 & 12 & ND & ND \\
S07 & 10 & ND & ND & ND \\
\hline S08 & 16 & ND & ND & 0.5 \\
\hline
\end{tabular}

ND: Not detected.

International Journal of

production. It might also be added to the alcoholic beverage as an adulterant. Acetone was not reported as a chemical component in a previous study [14]. Generally, acetone has a less toxicity potential in human and is moderately toxic to the liver; however, experimental studies revealed that acetone potentiates the liver toxicity of some chemicals by inducing microsomal enzymes which metabolize other chemicals to reactive toxic intermediates [21].

In our study, the organoleptic examination findings highlighted that the $\mathrm{pH}$ of the majority of alcoholic beverages was acidic. This data was consistent with that of a previous study [14]. The acidity nature of alcoholic beverages, especially fermented types, is due to the presence of organic acids, such as acetic acid, maleic acid, or tartaric acid [14].

This study is a pilot work about the analysis of toxic chemical components in illegal alcoholic beverages in the black market of Iran. A major limitation of this study was overlooking the analysis of other toxicologically-relevant compounds in illegal alcoholic beverages. Further studies are required with larger sample sizes from other geographical regions in Iran In this area. Besides, a comprehensive chemical analysis approach for investigating other chemicals (e.g., other long-chain alcohols, aldehydes, ketones, amides, organic acids, \& heavy metals) is suggested.

\section{Conclusion}

Methanol is a common toxic component with a high concentration in illegally-produced alcoholic beverages; it may generate acute toxicity after the consumption of its products. Furthermore, using acetone and propanol contaminated alcoholic beverages could be a risk factor for chronic alcoholic liver disease in the country. However, illegal alcohol consumption remains a critical public health problem in Iran. Thus, educational and preventive programs for the 
general population and healthcare providers are required to prevent methanol poisonings; strict legislations should be implemented against illegal alcohol producers.

\section{Ethical Considerations}

\section{Compliance with ethical guidelines}

This study was ethically approved by the Ethics Committee of the Faculty of Pharmacy, Islamic Azad University, Tehran, Iran (No. 986).

\section{Funding}

This research received no specific grant from funding agencies in the public, commercial, or non-profit sectors.

\section{Authors' contributions}

All authors contributed to in preparing this article.

\section{Conflict of interest}

The authors declared no conflict of interest.

\section{Acknowledgements}

We gratefully acknowledge all technical personnel of the Forensic Toxicology Laboratory of the Legal Medicine Center of Markazi province for their technical assistance.

\section{References}

[1] GBD 2016 Alcohol and Drug Use Collaborators. The global burden of disease attributable to alcohol and drug use in 195 countries and territories, 1990-2016: A systematic analysis for the Global Burden of Disease Study 2016. The Lancet, Psychiatry. 2018; 5(12):987-1012. [DOI:10.1016/S2215-0366(18)30337-7]

[2] Rehm J, Gmel GE Sr, Gmel G, Hasan OSM, Imtiaz S, Popova $\mathrm{S}$, et al. The relationship between different dimensions of alcohol use and the burden of disease: An update. Addiction. 2017; 112(6):968-1001. [DOI:10.1111/add.13757] [PMID] [PMCID]

[3] Rehm J, Room R, Graham K, Monteiro M, Gmel G, Sempos $\mathrm{CT}$. The relationship of average volume of alcohol consumption and patterns of drinking to burden of disease: An overview. Addiction. 2003; 98(9):1209-28. [DOI:10.1046/j.13600443.2003.00467.x] [PMID]

[4] Boffetta P, Hashibe Mia. Alcohol and cancer. Lancet Oncology. 2006; 7(2):149-56. [DOI:10.1016/S1470-2045(06)70577-0]

[5] Callaghan RC, Gatley JM, Veldhuizen S, Lev-Ran S, Mann R, Asbridge M. Alcohol- or drug-use disorders and motor vehicle accident mortality: A retrospective cohort study. Accident
Analysis and Prevention. 2013; 53:149-55. [DOI:10.1016/j. aap.2013.01.008] [PMID]

[6] Wolford-Clevenger C, Cropsey KL. Depressive symptoms and age of alcohol use onset interact to predict suicidal ideation. Death Studies. 2019; 2:1-7. [DOI:10.1080/07481187.2019. 1586798] [PMID]

[7] Lachenmeier DW, Ganss S, Rychlak B, Rehm J, Sulkowska U, Skiba M, Zatonski W. Association between quality of cheap and unrecorded alcohol products and public health consequences in Poland. Alcoholism: Clinical and Experimental Research. 2009; 33(10):1757-69. [DOI:10.1111/j.15300277.2009.01013.x] [PMID]

[8] Shadnia S, Rahimi M, Soltaninejad K, Nilli A. Role of clinical and paraclinical manifestations of methanol poisoning in outcome prediction. Journal of Research in Medical Sciences. 2013; 18(10):865-69. [PMID] [PMCID]

[9] Arslan MM, Zeren C, Aydin Z, Akcan R, Dokuyucu R, Keten A, Cekin N. Analysis of methanol and its derivatives in illegally produced alcoholic beverages. Journal of Forensic and Legal Medicine. 2015; 33:56-60. [DOI:10.1016/j. jflm.2015.04.005] [PMID]

[10] Karadeniz H, Birincioglu I. Methyl alcohol poisoning in Trabzon (Turkey). Journal of Forensic Science. 2011; 56(3):82224. [DOI: 10.1111/j.1556-4029.2011.01623.x]

[11] Hassanian-Moghaddam H, Nikfarjam A, Mirafzal A, Saberinia A, Nasehi AA, Masoumi Asl H, Memaryan N. Methanol mass poisoning in Iran: Role of case finding in outbreak management. Journal of Public Health. 2015; 37(2):354-59. [DOI:10.1093/pubmed/fdu038] [PMID]

[12] Taleb ZB, Bahelah R. Methanol poisoning outbreak in Libya: A need for policy reforms. Journal of Public Health Policy. 2014; 35(4):489-98. [DOI:10.1057/jphp.2014.17] [PMID]

[13] Lachenmeier DW, Haupt S, Schulz K. Defining maximum levels of higher alcohols in alcoholic beverages and surrogate alcohol products. Regulatory Toxicology and Pharmacology. 2008; 50(3):313-21. [DOI:10.1016/j.yrtph.2007.12.008] [PMID]

[14] Dadpour B, Hedjazi A, Ghorbani H, Khosrojerdi H, Vaziri SM, Malek Zadeh H, et al. Chemical components of noncommercial alcohol beverage samples: A study with the viewpoint of toxic components in Mashhad, Iran. International Journal of High Risk Behavior and Addiction. 2016; 5(2):e27831 [DOI:10.5812/ijhrba.27831] [PMID] [PMCID]

[15] Ghadirzadeh MR, Nazari SSH, Mirtorabi D, Fattahi A. Tramadol, methadone and benzodiazepines added to alcoholic beverages. Alcohol and alcoholism. 2019; 54(4):435-38. [DOI:10.1093/alcalc/agz043] [PMID]

[16] Massoumi G, Saberi K, Eizadi-Mood N, Shamsi M, Alavi M, Morteza A. Methanol poisoning in Iran: From 2000 to 2009. Drug and Chemical Toxicology. 2012; 35(3):330-3. [DOI 10.3109/01480545.2011.619193] [PMID]

[17] Paine A, Davan AD. Defining a tolerable concentration of methanol in alcoholic drinks. Human and Experimental Toxicology. 2001; 20(11):563-68. [DOI:10.1191/096032701718620864] [PMID]

[18] Aghababaeian H, Araghi Ahvazi L, Ostadtaghizadeh A. The methanol poisoning outbreaks in Iran, 2018. Alcohol and Alcoholism. 2019; 54(2):128-30. [DOI:10.1093/alcalc/agz005] [PMID] 
[19] Tsakiris A, Kallithraka S, Kourkoutas Y. Grape Brandy production, composition and sensory evaluation. Journal of the Science of Food and Agriculture. 2014; 94(3):404-14. [DOI:10.1002/jsfa.6377] [PMID]

[20] Lang K, Väli M, Szucs S, Adány R, McKee M. The composition of surrogate and illegal alcohol products in Estonia. Alcohol and Alcoholism. 2006; 41(4):446-50. [DOI:10.1093/alcalc/ ag1038] [PMID]

[21] US Department Of Health And Human Services. Agency for Toxic Substances and Disease Registry (ATSDR). 1994. Toxicological profile for acetone. Available from: https:/ / www.atsdr. cdc.gov/toxprofiles/tp21.pdf Accessed: 8 March 2020 
This Page Intentionally Left Blank 